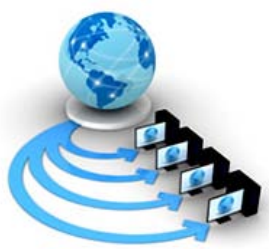

Volume 8, No. 7, July - August 2017

ISSN No. 0976-5697

International Journal of Advanced Research in Computer Science

RESEARCH PAPER

Available Online at www.ijarcs.info

\title{
THE ISSUES AND CHALLENGES IN FUTURISTIC DEVELOPMENT OF COGNITIVE RADIO NETWORKS
}

\author{
Nikita Bhagat \\ CSE Department \\ Gndu, Rc, Jalandhar
}

\author{
Dr. Jyoteesh Malhotra \\ CSE Department \\ Gndu, Rc, Jalandhar
}

\begin{abstract}
Due to the emergence of numerous applications based on wireless applications the problem of spectrum scantiness is increasing day by day. The utilization of spectrum has increased to its maximum level. To tackle this issue the technology named cognitive radio was introduced to the rescue. The cognitive radio is an emerging technology that enables dynamic spectrum access in wireless networks. The cognitive radio is capable of expediently using the obtainable portions of a licensed spectrum to improve the application performance for unlicensed users [1]. The opportunistic use of the accessible channels in the wireless environment requires dynamic channel assignment to efficiently utilize the available resources while minimizing the interference in the network. A lot of work has been reported in the literature so this paper presents a comprehensive survey on the current state-of-the-art, various technologies in which the cognitive radio technology can be used to enhance the performance to get better results are extracted in this paper. Open issues and emerging trends has been brought forward for the researchers working in the fields of wireless communication and network.
\end{abstract}

Keywords - Cognitive radio, Architectures, Current state-of-the-art, Open Issues and emerging trends, Futuristic use of cognitive radios.

\section{I.INTRODUCTION}

In this modern era of science and technology, where every person is aware of the latest technology and trends, every second person is holding mobile phone and using its resources in the well manner, this leads to the situation where a person need full access of the resources for which him/her paying. Now the situation has arise where the efficient utilization of resources is required. The craze of internet has increased as the smallest to the biggest thing is available on the internet, solution to every knowledge based problem is present on the internet .

At present, the information and communication technology commerce is facing global provocation in developing new services and products with enhanced Quality of Service (QoS). Undoubtedly, there is a keen call for global coherence not only in terms of energy, but also in terms of spectra available. In fact, the gap between supply and demand in wireless domain is increasing. With the shatter demand from smart phones to run bigger number of applications with paramount data rates will soon engulf the wireless capacity. The problem is the limited and costly available spectra to wireless data carriers. It has its slam not only on smart phones, but also on all wireless devices. In order to tackle the problem of spectrum underutilization, the concept of Cognitive Radio (CR) was proposed by Joseph Mitola III [1].The cognitive radio, built on a software-defined radio, is defined as an intelligent wireless communication system that is familiar of its environment and uses the technique of grasping by-building to learn from the environment and adapt to statistical variations in the input stimuli, with two primary objectives in mind highly dependable communication whenever and wherever needed well organized utilization of the radio spectrum [2].

Cognitive radio promises a low-cost, highly flexible alternative to the single-protocol wireless device, classic single-frequency band [3]. By sensing and adjusting to its environment, such a device is able to fill voids in the wireless spectrum and can dramatically increase spectral efficiency.

Main concern of cognitive radio is to make sure that cognitive user will not inhibit with the licensed user while communicating in licensed spectrum [4]. Based on available network information and other directives there are different undertaking by which secondary user access spectrum without interfering with primary user. These approaches include under lay, overlay and interweave paradigm [5] [6].

Interweaver paradigm uses opportunistic spectrum access method that was primary idea of cognitive radio. It is based on the fact of less utilization of spectrum which indicated that there are shot term space-time frequency holes that could be utilized by cognitive users [7][8]. Existence of these holes depends on time and geographical location. For systematic and interference free communication cognitive user needs activity based information of licensed and unlicensed users [9]. In more general perspective interweaver cognitive radios are smart systems that detect the unused spectrum opportunistically, utilizing it for communication and leaving the spectrum when primary user is detected thus avoiding considerable interference [9].

The cognitive radio channel is defined as a two-sender, tworeceiver interference channel in which sender 2 obtains the encoded message sender 1 plans to transmit. We keeping in mind two cases: in the genie-aided cognitive radio channel, sender 2 is non causally presented the data to be transmitted by sender 1 while in the causal cognitive radio channel, the data is get eventually. The cognitive radio at sender 2 may then select to transmit simultaneously over the same channel, as opposed to waiting for an idle channel as is traditional for a cognitive radio[10]. The cognitive radio is a spectrum agile system which has the ability to sense the communication environment dynamically and it can intelligently opt the communication parameters (bandwidth, carrier frequency, coding schemes, power, modulation scheme etc.) [11]. 
Cognitive user should be capable of sensing the environment for the estimation of accessible resources and application requirements and could opt their performance parameters according to user request and accessible resources. Secondary (cognitive) user can utilize the licensed spectrum (available white spaces) without influencing the priority utilization of the spectrum by primary user. In this way, it maximizes the efficient licensed spectrum utilization. The hardware provocations of cognitive radio are catered by artistries like Software define radio (SDR) [11] and Application specific integrated chips (ASIC) [12]. Considering the transmission and reception parameters, cognitive radios can be parted in to two categories :

Full cognitive radio, Spectrum sensing cognitive radio. Full Cognitive Radio is the type of cognitive radio in which almost every parameter of wireless node or network is considered [13]. In Spectrum-Sensing Cognitive Radio spectrum sensing cognitive radio only spectrum of radio frequency is considered [14].

Contribution of the paper includes work that has been done in the field of cognitive radio networks, manifestation of cognitive radio networks is done, summary of the work done and issues is tabulated below especially contribution of joseph mitola [1] in the term of tackling the problem of spectrum scarcity and spectrum utilization and various open issues and emerging trends in this technology.

This paper has been organized as follows: Section II gives the already reported work. Section III describe the current stateof-art and challenges resolved till date. The future Scope and possible mitigating solutions for the futuristic development of cognitive radio networks has been enumerated in the section before the paper is concluded in the section VI.

\section{II.RELATED WORK}

MAIN CONCERN OF COGNITIVE RADIO IS TO MAKE SURE THAT COGNITIVE USER WILL NOT INHIBIT WITH THE LICENSED USER WHILE COMMUNICATING IN LICENSED SPECTRUM. BASED ON AVAILABLE NETWORK INFORMATION AND OTHER DIRECTIVES THERE ARE DIFFERENT UNDERTAKING BY WHICH SECONDARY USER ACCESS SPECTRUM WITHOUT INTERFERING WITH PRIMARY USER. THESE APPROACHES INCLUDE UNDER LAY, OVERLAY AND INTERWEAVE PARADIGM [11] [12].

\section{a) Underlay Paradigm}

In this approach, secondary users simultaneously transmit with the primary users by maintaining endurable interference. This could be achieved by maintaining interference at primary receiver by secondary users below certain threshold [11] [12] [13].

\section{b) Overlay Paradigm}

In overlay technique interference is mitigated and in some cases completely denied as secondary user make use of codebook information and messages that primary user sends. In this way primary users assist secondary users for simultaneous transmission by using portion of their transmitting power.

\section{c) Interweaver Paradigm}

Interweaver paradigm uses opportunistic spectrum access method that was primary idea of cognitive radio. It is based on the fact of less utilization of spectrum which indicated that there are shot term space-time frequency holes that could be utilized by cognitive users. Existence of these holes depends on time and geographical location. For systematic and interference free communication cognitive user needs activity based information of licensed and unlicensed users [11]. In more general perspective interweaver cognitive radios are smart systems that detect the unused spectrum opportunistically, utilizing it for communication and leaving the spectrum when primary user is detected thus avoiding considerable interference [11].To summarize, both underlay and overlay techniques allow simultaneous transmission of primary and secondary users while interweaver paradigm avoids simultaneous transmission and uses opportunistic spectrum access method.

Table 1: showing the various cognitive radio networks.

\begin{tabular}{|c|c|}
\hline $\begin{array}{ll}\text { Cognitive } & \text { Radio } \\
\text { Architecture } & \end{array}$ & Architecture Type \\
\hline $\begin{array}{l}\text { OODA: } \\
\text { Loop for molding situations } \\
\text { requiring adaptation to } \\
\text { changing environment. }\end{array}$ & Simple.(easy to implement) \\
\hline $\begin{array}{l}\text { CECA: } \\
\text { Extension to OODA loop } \\
\text { used to model situations in } \\
\text { broader context. }\end{array}$ & Simple.(adaptive) \\
\hline $\begin{array}{l}\text { SOAR: } \\
\text { Used to develop systems that } \\
\text { possess intelligent behavior. } \\
\text { One of the first architectures } \\
\text { developed in cognitive and } \\
\text { artificial science } \\
\text { communities. }\end{array}$ & $\begin{array}{l}\text { Complex.(developing } \\
\text { concept) }\end{array}$ \\
\hline $\begin{array}{l}\text { Storm: } \\
\text { Extension to SOAR. It is } \\
\text { biologically inspired } \\
\text { architecture developed by } \\
\text { adopting knowledge } \\
\text { of psychology and brain } \\
\text { based science to original } \\
\text { SOAR architecture. }\end{array}$ & $\begin{array}{l}\text { Complex.(developing } \\
\text { concept) }\end{array}$ \\
\hline $\begin{array}{l}\text { ACT-R: } \\
\text { Modeled in a programming } \\
\text { language that is used to } \\
\text { represent tasks. The } \\
\text { developed models } \\
\text { are tested with respect to } \\
\text { tasks performed by real } \\
\text { people and comparing these } \\
\text { with tradition cognitive } \\
\text { psychology metrics. }\end{array}$ & $\begin{array}{l}\text { Complex.(developing } \\
\text { concept) }\end{array}$ \\
\hline
\end{tabular}

Channel Notching allows the CR-CPE to use the free sub channels that are not occupied by the incumbent, as compared to the standard case (without channel notching), where the entire channel is blocked even if the sub channels of the channel is being used by the Incumbent. Hence enabling channel notching will give more throughput [15]. 
The concept of dynamic spectrum access is the recognition of spectrum holes (a frequency band which is vacant enough to be used) or white spaces and uses them to communicate [15]. Dynamic spectrum access is the most essential application of cognitive radios. The PU bands are ingressly accessed by the SU networks such that the interference caused to the PUs is negligible. The scenario for dynamic spectrum access (DSA) where multiple PUs and SUs are coexisting .Coexistence of multiple secondary and primary user networks (heterogeneous or homogeneous) This is a process by which a radio system adjusts to available spectrum holes with restricted spectrum use rights dynamically, in response to varying circumstances and objectives: the created interference revamps the radio's state in environmental constraints . The principal task of DSA is to vanquish two types of interference are harmful interference caused by device malfunctioning and harmful interference caused by malicious user [16]. There are three main functions in Dynamic Spectrum Access are, cognitive processing, spectrum awareness and spectrum access. Spectrum awareness generates awareness about the Radio Frequency environment when spectrum access provides the ways to utilize the available spectrum opportunities for reclaim efficiently [17]. Cognitive processing is the intelligence and decision making function that performs several subtasks like designing sensing efficient, learning of the radio environment and access policies which manages interference for coexistence of the SU networks with the PU networks [17] .There are various methods of Dynamic spectrum access like game theoretic approach, a measurement based model for dynamic spectrum access, DSA using network coded cognitive control channel, Fuzzy logic based system. Among all of these models the Game theoretic approach is the most acceptable tool for CR systems [18].

\section{CURRENT STATE-OF-THE-ART}

A lot of work has been reported in the literature as tabulated below:

\begin{tabular}{|l|l|l|l|}
\hline Year & Author & Work done & Issues \\
\hline 1999 & $\begin{array}{l}\text { joseph } \\
\text { Mitola }\end{array}$ & $\begin{array}{l}\text { Concept of the } \\
\text { cognitive } \\
\text { radios is } \\
\text { introduced to } \\
\text { the world. }\end{array}$ & Spectrum scarcity \\
\hline 2004 & $\begin{array}{l}\text { w.Broderse } \\
\text { n,A.wolisz, } \\
\text { D. Cabric, } \\
\text { S.M. } \\
\text { Mishra, D. } \\
\text { Willkomm }\end{array}$ & $\begin{array}{l}\text { Corvus: } \\
\text { cognitive radio } \\
\text { approach for } \\
\text { usage of } \\
\text { virtual } \\
\text { unlicensed } \\
\text { spectrum }\end{array}$ & $\begin{array}{l}\text { Cross layer and } \\
\text { architecture }\end{array}$ \\
\hline 2005 & $\begin{array}{l}\text { Simon } \\
\text { Haykin } \\
\text { Natasha } \\
\text { Devroye, } \\
\text { Patrick } \\
\text { Mitran }\end{array}$ & $\begin{array}{l}\text { Various } \\
\text { architectures } \\
\text { and } \\
\text { classification } \\
\text { were } \\
\text { introduced to } \\
\text { implement } \\
\text { cognitive } \\
\text { radios }\end{array}$ & $\begin{array}{l}\text { Implementation of } \\
\text { cognitive radios }\end{array}$ \\
& $\begin{array}{l}\text { Joint power } \\
\text { requirement }\end{array}$ & $\begin{array}{l}\text { Allocation } \\
\text { spectrum }\end{array}$ \\
\hline 2008 & $\begin{array}{l}\text { Digham, } \\
\text { F.F }\end{array}$ \\
\hline
\end{tabular}

\begin{tabular}{|c|c|c|c|}
\hline & $\begin{array}{l}\text { Amna Saad } \\
\text { Kamil,Ibra } \\
\text { him } \\
\text { Khider, } \\
\text { R.andra } \\
\text { and } \\
\text { A. Sahai }\end{array}$ & $\begin{array}{l}\text { for } \\
\text { cognitive } \\
\text { radios., Open } \\
\text { Research } \\
\text { issues } \\
\text { Cognitive in } \\
\begin{array}{l}\text { Radio, SNR } \\
\text { walls for } \\
\text { signal } \\
\text { detection }\end{array} \\
\end{array}$ & $\begin{array}{l}\text { Cognitive Radios, } \\
\text { complexity, hidden } \\
\text { node }\end{array}$ \\
\hline 2009 & $\begin{array}{l}\text { Kim, S.J. } \\
\text { and G. B. } \\
\text { Giannakis }\end{array}$ & $\begin{array}{l}\text { Reduced- } \\
\text { Complexity } \\
\text { Sequential } \\
\text { Sensing } \\
\text { Algorithms for } \\
\text { Cognitive } \\
\text { OFDM } \\
\text { Radios. }\end{array}$ & $\begin{array}{l}\text { Achievable } \\
\text { optimal Rates in } \\
\text { Cognitive Radio } \\
\text { Channels }\end{array}$ \\
\hline 2011 & $\begin{array}{l}\text { Wang, M. } \\
\text { Ghosh, and } \\
\text { K. } \\
\text { Challapal }\end{array}$ & $\begin{array}{l}\text { to find many } \\
\text { "holes" r or } \\
\text { vacant spaces } \\
\text { in the radio } \\
\text { spectrum that } \\
\text { could be } \\
\text { exploited }\end{array}$ & $\begin{array}{l}\text { Spectrum } \\
\text { utilization }\end{array}$ \\
\hline 2012 & $\begin{array}{l}\text { Kaustav } \\
\text { ghosh, } \\
\text { Zurutuza }\end{array}$ & $\begin{array}{l}\text { India Security } \\
\text { issues and } \\
\text { challenges in } \\
\text { cognitive radio } \\
\text { network, } \\
\text { Cognitive } \\
\text { Radio, } \\
\text { Fundamental } \\
\text { Performance } \\
\text { Analysis for } \\
\text { Interweave } \\
\text { Opportunistic } \\
\text { Access Model. }\end{array}$ & $\begin{array}{lr}\text { Attacks } & \text { on } \\
\text { cognitive } & \text { radio } \\
\text { networks, } \\
\text { Most appropriate } \\
\text { architecture } \\
\text { follow }\end{array}$ \\
\hline 2013 & $\begin{array}{l}\text { Gyanendra } \\
\text { Prasad } \\
\text { Joshi, } \\
\text { Seung } \\
\text { Yeob Nam } \\
\text { and Sung } \\
\text { Won Kim }\end{array}$ & $\begin{array}{l}\text { Cognitive } \\
\text { Radio } \\
\text { Wireless } \\
\text { Sensor } \\
\text { Networks: } \\
\text { Applications, } \\
\text { Challenges } \\
\text { and Research } \\
\text { Trends }\end{array}$ & $\begin{array}{l}\text { Energy Efficiency } \\
\text { Avoiding Attacks }\end{array}$ \\
\hline 2014 & $\begin{array}{l}\text { Gyanendra } \\
\text { Prasad } \\
\text { Joshi, } \\
\text { Seung } \\
\text { Yeob Nam } \\
\text { and Sung } \\
\text { Won Kim }\end{array}$ & $\begin{array}{l}\text { Recent } \\
\text { Security Issues } \\
\text { on Cognitive } \\
\text { Radio } \\
\text { Networks }\end{array}$ & $\begin{array}{l}\text { Configuration Data } \\
\text { Corruption }\end{array}$ \\
\hline 2015 & $\begin{array}{l}\text { Gyanendra } \\
\text { Prasad } \\
\text { Joshi, } \\
\text { Seung } \\
\text { Yeob Nam } \\
\text { and Sung } \\
\text { Won Kim }\end{array}$ & $\begin{array}{l}\text { Channel } \\
\text { Assignment } \\
\text { Algorithms in } \\
\text { Cognitive } \\
\text { Radio } \\
\text { Networks: } \\
\text { Taxonomy, } \\
\text { Open Issues, } \\
\text { and }\end{array}$ & $\begin{array}{l}\text { Channel } \\
\text { assignment }\end{array}$ \\
\hline
\end{tabular}




\begin{tabular}{|l|l|l|l|}
\hline & & Challenges & \\
\hline 2016 & Jagsir & Effect of & OFDM, spectrum \\
& singh,roopa & OFDM in & utilization \\
& li garg & Cognitive & \\
& \&inderdeep & Radio: \\
& kaur aulakh & $\begin{array}{l}\text { Advantages \& } \\
\text { Issues }\end{array}$ & \\
\hline
\end{tabular}

\section{OPEN ISUUES AND EMERGING TRENDS}

A lot of work has been reported in the literature as tabulated in the previous section, However there is a simple scope in the further development in this area for the effective utilization of spectrum. The major areas related to CRN have been highlighted below:

\section{Spectrum issues:}

\section{Spectrum management}

Cognitive radios have an enormous potential to improve spectrum utilization by allowing the Secondary Users to access the spectrum dynamically lacking interfering licensed PUs. A major challenge in operating these radios as a network is how to carry out an efficient and effective Medium Access Control (MAC) system that can malleably and proficiently assign transmission powers and bands among Cognitive radios according to the changing environment. Mostly, this issue is resolved through suboptimal empirical approaches or centralized solutions [18].

Spectrum Utilization

It is this discrepancy between FCC allotments and actual usage, which argues that a new strategy of spectrum licensing is needed [19]. Need of the hour is an overture, which provides an improvement and efficiency of unlicensed usage to other spectral bands, while adjusting the present users who receive top priority (PUs) and enabling future systems a more flexible spectrum access. [18]

Spectrum sharing strategies

Spectrum sharing is the allotment of an unused spectrum bands that could be utilized for unlicensed or shared services. Opportunistic communication with interference avoidance faces a large number of challenges in the detection of sharing in multi-user CRS. Due to the presence of user priority (either primary and secondary), they possess unique design challenges that are not yet met in conventional wireless systems. A major issue in the cooperative environment is sharing, a matter that has created a lot of research interest in the recent past[18].

Spectrum Decision

Since CR works on decision making, the first research challenge is where and how the decision concerning spectrum availability, channel selection or access, or performance optimization should be counted. Firstly, decision is related to the way in which the cognitive system works i.e., centralized or distributed. This facet is more significant for both cognitive networks, where intelligence is likely to be distributed, and cognitive radios, as decision making could be impacted by cooperation between them and also with other devices. Secondly, the choice of the decision algorithms like neural networks, genetic algorithms, particle swarm optimization, ant-colony optimization, etc. which should be customized to extend through the CRS requirements [20].

\section{Hidden node and sharing issues}

Apart from adding complication to the cognitive device, however, none has clearly solved the 'Hidden Node' muddle. There is a presence of a PU receiver in the region covered by the CR transmission. The CR doesn't notice the PU signal because of its low power. The result is unwanted noise at the PU receiver. In order to ensure proper working of PU signals Hidden Node problem must be resolved. In addition, the link for communication must be dependable and requires a way to forecast link stability by analyzing spectrum usage patterns through a technique called Radio Environment Mapping (REM).[20] [18]

\section{Geo-location}

Geo-location is an enabling technology because of wide range of applications resulting from the information of radio's current position and possibility being familiar of its projected route and objective. When $\mathrm{CR}$ uses the Geo-location technology for finding location combined with a database look-up, each Access Point (AP) may be connected to one, or multiple databases which provide information on the unutilized TVWS channels that are present at the location of AP and provide information on utmost transmitted power levels applied in each channel [20]. In addition, master-slave technology is used so that the necessary functionalities for database search and channel selection need to be carried out only in APs. It maintains the cost of end-user devices and complications to lowest.

Entirely the same, the challenges in this area are how to execute the database, and how to operate it. Providing mandatory (PUs) databases need knowledge of the locations of CR devices with fixed precision. If CR devices are outdoors and equipped with GPS systems, obtaining their Geo-locations may still be less a technical challenge.

\section{Cross-Layers}

The flexibility in CRs has major implications for the design cross-layer algorithms which adapt to alterations in physical channel quality, wireless noise, network topology, traffic demand or radio node density may be anticipated to take an advanced command and management framework with support for cross-layer information. Spectrum mobility and frequency band handoff management will face some new trials which are needed to perform a cross-layer design, particularly when required providing the essential capabilities in terms of QoS at the same time [21].

\section{Integrity and Security}

The CRS should ensure secure device operations. Security includes enforcement of regulations. Major challenges include equipment authorization requiring amount of resources for imposition in static systems, the requirement of obtaining evidence that violations occurred, and the intent of the violator's identities. As the systems move towards dynamic nature, there are increased number of possible interactions that can lead to a violation. The leading challenge is on equipment authorization, especially on evaluation standards and security documentation. It turns yet more troublesome with the exercise of self-learning mechanisms. Software and hardware certification will not ensure conformation of device to the operational envelopes. The security of the software and software certification and are also challenging area, especially when the software controls dynamic systems. Security of software is critical to ensure that rogue behavior is not programmed into the devices. The number of combinations of interactions is high and the mobility and the agility of CRS is great, then the monitoring mechanisms are challenging tasks. 
The data should not be modified or changed during the transmission leads to the attainment of integrity factor in the cognitive radio networks [21].

\section{Complexity issue}

Cognitive radio is a future slip path of tackling the problem of the increasingly radio spectrum. To achieve this, it postulates that the communications nodes themselves are capable of feeling, and dynamically selecting, and allocating the appropriate spectral resources without causing much interference to other users. To achieve this researchers are advising a variety of mixed methods for implementing cognitive radio, which include software defined radio (SDR), and intelligence, dynamic spectrum management[19][21]. The challenge is to see whether such complexity is rational, and to check its feasible outcomes to overcome the current regulatory constrained spectral assignment process. It is anticipated that it should be promising to thrive reduced complexity strategies that will surrender much of the functionality of projected systems, enabling rapid adoption, and wider use in systems where cognitive radio is presently not being debated due to prohibitive complexity. [18]

The challenges remain numerous, namely, intelligence distribution and implementation, delay/protocol overhead, security, cross-layer design, sensing algorithms, and flexible hardware design. The objective of this part is to put light on the challenges which are presently under debate in the framework of research on CRS.

\section{EMERGING TRENDS}

Cognitive radio networks can be considered to the major contributor in various emerging networks and technologies such as enumerated below:

Cognitive radio technology in $5 G$ wireless communication networks:

Wireless system designers have been facing the continuously increasing demand for high data rates and mobility required by new wireless applications and therefore have initiated research on fifth generation wireless systems that are supposed to be deployed beyond 2020. In interference-free CR networks, CR users are allowed to borrow spectrum resources only when licensed users do not utilize them. A key to enabling interference- free CR networks is figuring out how to detect the spectrum holes (white space) that spread out in wideband frequency spectrums. CR receivers should first supervise and allocate the unused spectrums via spectrum sensing (or combining with geo location databases) and feed this information back to the CR transmitter. A correlating mechanism is required in multiple CR networks that try to access the same spectrum to prevent users colliding when accessing the matching spectrum holes. In interferencetolerant CR networks, CR users can dispense the spectrum resource with a licensed system while keeping the interference below a threshold. In comparison with interference-free CR networks, interference-tolerant CR networks can attain enhanced spectrum utilization by opportunistically sharing the radio spectrum resources with licensed users, as well as better spectral and energy efficiency. The 5G CR network is an innovative software defined radio technique which has been considered as one of the promising technologie014.s to improve the utilization of the congested RF spectrum. Taking on CR is motivated by the fact that a large portion of the radio spectrum is underutilized most of the time [22].

Cognitive radio technology in Wide Area Networks:

Since users can share spectrum, the demand for special use licenses should be reduced. As blocks of spectrum become available, a policy of converting them to shared-access bands would evade the need for auctions and stimulate development. Much as automobiles are subject to pollution and safety requirements, cognitive radio technologies could be required to meet ever increasing requirements for effective etiquette , spectral efficiency and resistance to interference. It is noteworthy that the WAN concept has the potential to explicitly protect the spectrum rights of mandatory license holders. License holders can be assured immediate and top priority access to their spectrum and all spectrum made available for WAN use on a temporary basis could be rapidly retrieved by the primary license holder if needed. A good example of this is the potential for shared use of spectrum reserved today for military use. In most parts of the country, this spectrum goes unutilized most of the time, making it ideal for shared use spectrum. However, in the event of an emergency, a network based system such as the UWAN could easily remove the full band on a nationwide level for immediate and exclusive military use [23]. This ability is also critical to cellular operators, where the large additional spectrum pool, dramatically reduced costs, and ability to assure service through use of incumbent licensed spectrum makes the UWAN very attractive [24]. The cellular wireless market has started the transition to data centric services including high speed internet access, high quality audio, video and gaming. Communications technology can meet the requirement for very high data link speeds, and can also refine network throughput, but dramatically more spectrum will be needed to provide ubiquitous wireless data service [25].

\section{OFDM for Cognitive radio:}

For CR to achieve this objective, the physical layer (PHY) must be highly flexible and adaptable. A special case of multicarrier transmission known as orthogonal frequency division multiplexing (OFDM) is one of the most widely used technologies in recent wireless communications systems. OFDM has the potential of fulfilling the aforementioned requirements of CR inherently or with minor modifications. Due to its attractive features, OFDM has been successfully used in numerous wireless standards and technologies. We believe that OFDM also will play an important role in realizing the concept of CR by providing a proven, scalable, and adaptive technology for air interface [26].

The underlying sensing and spectrum shaping capabilities of OFDM, together with its flexibility and adaptively, probably make it the best transmission technology for CR systems. OFDM is a multi-carrier modulation technique that can overcome many problems that arise with high bit-rate communications, the most serious of which is time diffusion. The data-bearing symbol stream is split into several lower-rate streams, and these streams are transmitted on different carriers. Because this splitting increases the symbol length by the number of orthogonally overlapping carriers (subcarriers), multipath echoes affect only a small portion of the neighboring symbols [27]. The remaining inter-symbol interference (ISI) is removed by extending the OFDM symbol with a cyclic prefix (CP). Using this method, OFDM reduces the dispersion effect of multipath channels encountered with high data rates and 
reduces the requirement for complex equalizers. Other advantages of OFDM include high spectral efficiency, robustness against narrowband interference (NBI), scalability, and easy implementation using fast Fourier transform (FFT)[28].

\section{CONCLUSION}

Spectrum is a valuable resource in the wireless communication systems. Cognitive radio, which is one of the efforts to utilize the obtainable spectrum more efficiently through opportunistic spectrum usage, has become a stimulating and promising concept. One of the essential elements of cognitive radio is sensing the obtainable spectrum opportunities. In this paper some of the cognitive radios issues used to diagnose the effectiveness in wireless communication. These characteristics are crucial when applying the cognitive radios in order to diagnose the effectiveness and reliability of wireless networks. Based on the comprehensive survey on the available literature the important issues related to spectrum management and its sharing strategies has been received other open issues such as use of cross layer approach, geo location, integrity and security has also been discussed. CRNs can be considered to the major contributor in various emerging networks and technologies such as 5G, wide area networks, OFDM and will be the part of various wireless technology standards. It is hope that the work done here in this paper will be ready reference for the researchers working in wireless communication and networks in general and cognitive radios in particular.

\section{REFERENCES}

[1] Joseph Mitola III and G. Q. Maguire, “Cognitive radio: making software radios more personal," IEEE Personal Communications, vol. 6, no. 4, pp. 13-18, 1999.

[2] Simon Haykin, Life Fellow,,” Cognitive Radio: BrainEmpowered wireless Communications”, IEEE JOURNAL ON SELECTED AREAS IN COMMUNICATIONS, vol. 23, no. 2, February 2005.

[3] Natasha Devroye, Patrick Mitran, Student Member, IEEE, and Vahid Tarokh," Achievable Rates in Cognitive Radio Channels", IEEE transaction on information theory, vol. 52, no. 5, MAY 2006.

[4] Kim, S.J. and G. B. Giannakis, 2009. Rate Optimal and ReducedComplexity Sequential Sensing Algorithms for Cognitive OFDM Radios. In the proceedings of 2009 43rd annual conference on Information Science and Systems, pp: 141-146.

[5] Mitola, J., G.Q. Maguire, 1999. Cognitive Radio:Making Software Radios More Personal. J. of Personal Communication, IEEE., 6 (4): 13-18.

[6] Zhang, Q., G.J.M. Smit, L.T. Smit, A. Kokkeler, F.W. Hoeksema and M. Heskamp, 2005. A Reconfigurable Platform for Cognitive Radio. In the proceedings of 2005 2nd International Conference on Mobile Technology, Applications and Systems, pp: $1-5$.

[7] Haykin, S., 2005. Cognitive Radio: Brain-Empowered Wireless Communication. IEEE Journal on Selected Areas in Communications. 23 (2): 201-220.

[8] Digham, F.F., 2008. Joint Power and Channel Allocation for Cognitive Radios. In the proceedings of 2008 Wireless Communications and Networking Conference, pp: $882-887$.
[9] Alex, Z.C., Sivaraman and S.K. Vasudevan, 2010. Software Defined Radio Implementation (With simulation \& analysis).Intl. J. of Computer Applications., 4 (8): 21-27.

[10] Mitola, J., 2000. Software Defined Radio Architecture Evolution: Foundations, Technology Tradeoffs, and Architecture Implementations. IEICE Transactions on Communications, E83-B (6):1165-1173.

[11] Zurutuza, N., 2012. Cognitive Radio, Fundamental Performance Analysis for Interweave Opportunistic Access Model. www.stanford.edu/ naroa/ee359project.pdf.

[12] Goldsmith, A., S.A. Jafar, I. Maric', and S. Srinivasa, 2009. Breaking Spectrum Gridlock with Cognitive Radios: An Information Theoretic Perspective. J. of the IEEE., 97 (5): 894914.

[13] Wang, B., and K. J. Ray Liu, 2011. Advances in Cognitive Radio Networks: A Survey. IEEE J. of Selected Topics in Signal Processing,. 5 (1): 5-23.

[14] Reed, J., C. Bostian, 2006. Understanding the Issues in Software Defined Cognitive Radio,” in Dyspan, Dublin, Ireland.

[15] Shankar, S.N., 2007. Squeezing the Most Out of Cognitive Radio: A Joint MAC/PHY Perspective. In the proceedings of 2007 IEEE International Conference on Acoustics, Speech and Signal Processing, pp: 1361-1364.

[16] nKaustav Ghosh* Department of Computer Science, St. Xaviers College Autonomous (Kolkata), "India Security issues and challenges in cognitive radio network : a comprehensive study”, ACCENTS Transactions on Information Security, Vol 1(1) ISSN (Online): 2455-7196

[17] J. Wang, M. Ghosh, and K. Challapali, "Emerging cognitive radio applications: a survey,” IEEE communication magazine, vol. 49, no. 3, pp. 74-81, 2011.

[18] Amna Saad Kamil, and Ibrahim Khider “Open Research issues in Cognitive Radio"16thTelecommunications Forum TELFOR, Serbia , Belgrade, 25-27 Nov., 2008.

[19] R.W. Brodersen, A. Wolisz, D. Cabric, S.M. Mishra, D. Willkomm, "Corvus: a cognitive radio approach for usage of virtual unlicensed spectrum”, Berkeley Wireless Research Center (BWRC) White paper, 2004.

[18] Eamonn O Nuallain, “A Proposed Propagation-based Methodology with which to address the Hidden Node Problem and Security/Reliability Issues in Cognitive Radio", 4th International Conference on Wireless Communications, Networking and Mobile Computing, 2008. WiCOM '08.

[19] Raul Etkin, Abhay K. Parekh, David Tse, "Spectrum Sharing for Unlicensed Bands," IEEE Journal on Selected Areas in Communications, vol. 25, pp. 517-528, April 2007.

[20] http://www.hindawi.com/journals/vlsi/2012/716476/

[21] J. Arias, L. Quintanilla, J. Segundo, L. Enríquez, J. Vicente, and J. M. Hernández-Mangas, "Parallel continuous-time $\Delta \Sigma$ ADC for OFDM UWB receivers," IEEE Transactions on Circuits and Systems I, vol. 56, no. 7, pp. 1478-1487, 2009.

[22] Federal Communications Commission, "Spectrum Policy Task Force”, Rep ET Docket no.02-135,Nov. 2002

[23] R. Tandra and A. Sahai, "SNR walls for signal detection," IEEE Journal on Selected Topics in Signal Processing, vol. 2, no. 1, pp. 4-17, 2008.

[24] Jagsir Singh, Roopali Garg \& Inderdeep Kaur Aulakh, "Effect of OFDM in Cognitive Radio: Advantages \& Issues”, Second 
International Conference on Computational Intelligence \& Communication Technology,2016

[25] Goutam Ghosh1 , Prasun Das2 and Subhajit Chatterjee3," Cognitive Radio And Dynamic Spectrum Access - A Study”, International Journal of Next-Generation Networks (IJNGN) Vol.6, No.1, March 2014.

[26] Cheng-Xiang Wang, Fourat Haider, Xiqi Gao and Xiao-Hu You, Yang Yang, Dongfeng Yuan, Hadi M. Aggoune, Harald Haas, Simon Fletcher, Erol Hepsaydir," Cellular Architecture and
Key Technologies for 5G Wireless Communication Networks”, IEEE Communications Magazine,2014

[27] William Krenik and Anuj Batra,” Cognitive Radio Techniques for Wide Area Networks", IEEE Communications Magazine,2014

[28] Hisham a. Mahmoud, Tevfik Yucek and Huseyin Arslan,” OFDM For Cognitive Radio: Merits and Challenges”, IEEE Wireless Communications, April 2009. 